\title{
Assessment of Physical and Chemical Properties of Soil Samples in Kaipad Tracts of Kannur District, India
}

\author{
G.R. Santhi*, N.K. Binitha, P.R. Suresh and N.L. Ebimol
}

Department of Soil Science \& Agricultural Chemistry, College of Agriculture, Kerala

Agricultural University, Padannakkad, Kasaragod-671314, Kerala, India

*Corresponding author

\section{A B S T R A C T}

A study was conducted during April 2016 to assess the different physical and chemical properties of the soil of Kaipad tracts. The Kaipad tracts, characterized by the unique saline hydromorphic soil covers the north Malabar districts of Kozhikode, Kannur and

\section{Keywords}

Saline hydromorphic soil, Kaipad, Physical and chemical properties.

\section{Article Info}

Accepted:

12 September 2017

Available Online:

10 November 2017 Kasaragod. As a part of the investigation, representative surface soil samples were collected from 15 selected locations of Kaipad areas comprising of Muttil and Cherukunnu (Fig. 1) panchayath during the first week of April 2016 to assess the different physical and chemical properties. The depth of sampling was 0 to $15 \mathrm{~cm}$. The GPS data for the sites of sampling were also recorded. The soil samples collected from each site was brought to College of Agriculture, Padannakkad, dried under shade, labelled and stored in clean polythene bags. The moisture percentages of the fresh soil samples were estimated gravimetrically. The various physical and chemical properties of soil samples such as bulk density, textural analysis, $\mathrm{pH}$, electrical conductivity, organic carbon, available $\mathrm{N}, \mathrm{P}, \mathrm{K}$, $\mathrm{Ca}, \mathrm{Mg}, \mathrm{S}, \mathrm{Fe}, \mathrm{Zn}, \mathrm{Cu}, \mathrm{Mn}, \mathrm{B}, \mathrm{Si}$, exchangeable $\mathrm{Na}$ and $\mathrm{Al}$ and cation exchange capacity were estimated using the standard procedures. The results revealed that the macro and micro nutrient status of Kaipad soils was generally very high except in case of magnesium. The high CEC observed in these soils might be due to the high organic matter content of these soils.

\section{Introduction}

The Kaipad tracts, characterized by the unique saline hydromorphic soil covers the north Malabar districts of Kozhikode, Kannur and Kasaragod of Kerala. These coastal wetlands are located approximately between the GPS coordinates $11.25^{\circ} \mathrm{N} 75.77^{\circ} \mathrm{E}$ and $12.5^{\circ} \mathrm{N} 75.0^{\circ} \mathrm{E}$ (Vanaja, 2013). The Kaipad tract covers an area of about 4100 hectares (Vanaja, 2013), a major extent of which about 2500 hectares is located in the Kannur district of Kerala. These are brackish water tracts embellished with high inherent organic matter content and essential nutrients thereby having a high production potential. An integrated system of rice cultivation and aquaculture is practised here. Rice farming in these tracts is implemented in a special way, which is purely dependent on the monsoon and the tidal effects. The 'Kaipad' rice which is cultivated in the coastal wetlands of Kerala has been included in the Geographical Indications (GI) registry which is a part of the Intellectual Property regime. Pedologically, these soils are dominated by the presence of different iron 
and sulphur containing minerals like pyrite and jarosite.

Rice cultivation is practised here during the first season in the low to medium saline phase of production cycle during June to October after the onset of monsoon showers. These areas are subjected to periodic floods in the monsoon and prevalence of high salinity during the summer seasons. The entry of salt water from the sea during the summer months leads to the salinization of these soils. Further, this salinity gets washed off by the south-west monsoon leading to decline in the salinity levels. Rice cultivation is carried out by the preparation of mounds during the month of April/ May. Then, after the first showers of monsoon, the sprouted seeds are sown on top of these mounds. After 45 days, the mounds are disassembled without causing any damage to the rice roots and spread uniformly.

The rice crop is harvested in NovemberDecember after which shrimp culture is taken up in these lands. During harvest, the panicles are cut along with small portion of the culm leaving behind greater part of the stubbles in the field, which adds to the organic matter content to these soils.

Due to the shrinking area under cultivation, the greatest potential for expansion of cultivable land under rice lies in these wetlands. As long as the population tends to increase in the developing countries, the demand for food production also grows. Efforts have to be put in to expand the area under cultivation and thereby stabilize food security. Crop productivity enhancement in cultivated lands is also a strategy. Thus it is necessary to study the chemistry of these soils. Rice is the major crop suited for the wetland ecosystems. And proper emphasis has to be laid to improve and expand rice production in these unexplored new areas.

\section{Materials and Methods}

Kaipad tracts, comprising the saline hydromorphic soils are distributed in the north Malabar districts of Kozhikode, Kannur and Kasaragod of Kerala. These coastal wetlands lies between $11.25^{\circ} \mathrm{N} 75.77^{\circ} \mathrm{E}$ and $12.5^{\circ} \mathrm{N} 75.0^{\circ} \mathrm{E}$. As a part of the study, representative surface soil samples were collected from 15 selected locations of Kaipad areas comprising of Muttil and Cherukunnu (Fig. 1) panchayath during the first week of April 2016 to assess the different physical and chemical properties. The depth of sampling was 0 to $15 \mathrm{~cm}$. The GPS data for the site of sampling were also recorded. The details of the location along with GPS coordinates are given in Table 1. The soil samples collected from each site was brought to College of Agriculture, Padannakkad, dried under shade, labelled and stored in clean polythene bags. The moisture percentages of the fresh soil samples were estimated gravimetrically. The various physical and chemical properties (Tables 2 and 3 respectively) of soil samples such as bulk density, textural analysis, $\mathrm{pH}$, electrical conductivity, organic carbon, available N, P, $\mathrm{K}, \mathrm{Ca}, \mathrm{Mg}, \mathrm{S}, \mathrm{Fe}, \mathrm{Zn}, \mathrm{Cu}, \mathrm{Mn}, \mathrm{B}, \mathrm{Si}$, exchangeable $\mathrm{Na}$ and $\mathrm{Al}$ and cation exchange capacity were estimated using the standard procedures.

\section{Results and Discussion}

The bulk density varied from $1.06 \mathrm{Mgm}^{-3}$ in location number 11 to $1.17 \mathrm{Mgm}^{-3}$ in location number 9 with a standard deviation of 0.032 . The textural classification revealed that eleven of the sampled locations had sandy clay loam texture. The texture varied from sandy loam to sandy clay loam as in Table 2 . The sand content varied from 47.32 to 68.32 $\%$. The silt content ranged from 12.14 to $27.31 \%$. Clay content varied between 17.15 to $28.14 \%$. The loamy nature may be related to 
the fluffiness of the soil. The predominant fraction observed in the sampled locations was sand. The moisture percentage in the soil samples varied from $15.27 \%$ to $86.76 \%$ in location number 10 to location number 7 . The mean $(31.98 \%)$ and standard deviation values (19.38) were also obtained.

\section{Soil reaction $(\mathbf{p H})$}

The soil reaction of the samples analysed during the summer month of April ranged from 3.40 to 6.48 (Table 3 ) in fifteen different locations of Kaipad. The results revealed that there was a wide variation in $\mathrm{pH}$ ranging from ultra-acidic to slightly acidic pH (Figure 2). This is in concordance with the report of Nair and Money (1972). They reported that soil $\mathrm{pH}$ of the saline soils of Kerala varied from 3.0 to 6.8. The slightly acidic $\mathrm{pH}$ noticed in Kaipad soils might be attributed to the presence of lime shell depositions (Iyer, 1989) as a result of frequent saline water intrusions during the monsoon period. The ultra-acidic $\mathrm{pH}$ noticed in Kaipad soils might be related to the presence of pyrite and other iron bearing minerals such as jarosite, limonite etc.

\section{Electrical conductivity}

The range of electrical conductivity recorded in the soil samples of Kaipad was from 9.72 to $29.00 \mathrm{dSm}^{-1}$. This high salinity recorded during the summer months might be attributed to the extremely high accumulation of salts during the dry season period. Similar findings on electrical conductivity of Kaipad soil was reported by Chandramohan and Mohanan (2012). They reported that the electrical conductivity of these soils ranged from 10.9 to $19.9 \mathrm{dSm}^{-1}$ during the summer months. These salts get washed away during the onset of monsoon and thus cause a reduction in electrical conductivity of soils, which favours rice cultivation. Saline tolerant rice varieties can be cultivated when the soil electrical conductivity falls below $6 \mathrm{dSm}^{-1}$
(Shylaraj and Sasidharan, 2005). The most popular saline tolerant rice varieties of Kaipad are Kuthiru and Ezhome-1. Kuthiru is a saline tolerant lodging land race widely grown in Kaipad regions and Ezhome-1 is a high yielding long duration variety which is tolerant from low to medium salinity (Vanaja et al 2015).

\section{Organic carbon}

The organic carbon status of the sampled locations of Kaipad varied between 0.53 to 3.34 percentages over the fifteen locations. About 7 per cent of the sampled locations recorded medium organic carbon content and 93.67 per cent of the sampled locations recorded high organic carbon per cent. The relatively high organic carbon in the Kaipad soils might be attributed to the incorporation of stubbles and straw after harvest of rice crop in the field itself or from the remnants of the rice shrimp cultivation practised in Kaipad during the high saline regime prevailing from November to April. It may also be attributed to the diverse flora and fauna present in the soils of Kaipad.

\section{Available macronutrients}

The results revealed that the macronutrient content of Kaipad soils was generally very high.

The available nitrogen status of the sampled locations of Kaipad regions varied from $173.47 \mathrm{kgha}^{-1}$ to $1083.80 \mathrm{kgha}^{-1}$ with a mean value of $544.95 \mathrm{kgha}^{-1}$. About 7 per cent of the sampled locations were low in nitrogen content, 60 per cent medium and 33.7 per cent had high nitrogen content. This medium to high value of available nitrogen content may be due to the presence of high amount of organic matter in these soils and the faster mineralization of nitrogen due to the activity of micro-organisms (Leiroset al 1999). 
The available phosphorus content varied from $8.65 \mathrm{kgha}^{-1}$ in location number 6 to 50.27 $\mathrm{kgha}^{-1}$ in location number 10 . The available phosphorus contents of about 13.33 per cent of the locations were low, 40 per cent medium and 46.67 per cent were high. Chandramohan and Mohanan (2012) reported that the available soil phosphorus content in Kaipad soils ranged from $7.2 \mathrm{~kg} \mathrm{ha}^{-1}$ to $34.2 \mathrm{~kg}$ ha ${ }^{1}$.Nair and Money (1972) as well as Samikutty (1977) reported that the saline soils of Kerala were deficient in phosphorus contents.

Samikutty (1977) reported that these soils are generally poor in phosphates. Padmakumaret al. (2002) indorsed that tidal influence in estuarine situations can be linked to the high intensity of plant nutrients such as nitrates and phosphates. The available potassium content observed in all the sampled soils was extremely high ranging from 1239 to 3391 $\mathrm{kgha}^{-1}$. This may be linked to the incorporation of paddy stubbles in the soil after paddy cultivation or due to the excrements which get deposited during the practice of aquaculture in the high saline periods of November to April. It was reported by Samikutty (1977) that the sodium and potassium contents in these soils are higher than those of the other paddy soils of Kerala. He explained that this is due to the continuous submergence of these soils with salt water for over six to eight months in a year and the recurrent barrage by the brackish waters owing to the tidal effect. The available calcium contents recorded from the 15 locations were very high ranging from 826.25 $\mathrm{mgkg}^{-1}$ to $1919.67 \mathrm{mgkg}^{-1}$. This extremely high calcium content in the sampled locations might be attributed to the presence of lime shell depositions associated with iron pyrite. The rice shrimp farming practiced in the Kaipad tracts might also have contributed to the high calcium content in the Kaipad soils. Similar findings were reported by Iyer (1989) in the Kaipad soils.

Table.1 Details of the location along with GPS coordinate

\begin{tabular}{|l|l|l|l|}
\hline S. No. & Locations & North latitude & East longitude \\
\hline 1. & Punnachery & $12^{\circ} 016^{\prime} .28^{\prime \prime}$ & $75^{\circ} 17^{\prime} 20^{\prime \prime} .88$ \\
\hline 2. & Punnachery & $12^{\circ} 017^{\prime} .78^{\prime \prime}$ & $75^{\circ} 17^{\prime} 19^{\prime \prime} .85$ \\
\hline 3. & Punnachery & $12^{\circ} 015^{\prime} .79$ & $75^{\circ} 17^{\prime} 18^{\prime \prime} .55$ \\
\hline 4. & Punnachery & $12^{\circ} 019^{\prime} .15^{\prime \prime}$ & $75^{\circ} 17^{\prime} 16^{\prime \prime} .09$ \\
\hline 5. & Valiyamthuruthy Kaipad & $12^{\circ} 012^{\prime} .68$ & $75^{\circ} 18^{\prime} .056$ \\
\hline 6. & Pallikkara & $12^{\circ} 032^{\prime} .74$ & $75^{\circ} 16^{\prime} 14^{\prime \prime} .06$ \\
\hline 7. & MuttilVadakk (Pallikkara Moolaaykkil) & $12^{\circ} 029^{\prime} .81$ & $75^{\circ} 16^{\prime} 15^{\prime \prime} .01$ \\
\hline 8. & Muttil & $12^{\circ} 030^{\prime} .39$ & $75^{\circ} 16^{\prime} 17^{\prime \prime} .42$ \\
\hline 9. & Muttil & $12^{\circ} 030^{\prime} .62$ & $75^{\circ} 16^{\prime} 18^{\prime \prime} .72$ \\
\hline 10. & Muttil (Fallow land) & $12^{\circ} 028^{\prime} .40$ & $75^{\circ} 16^{\prime} 60^{\prime \prime} .25$ \\
\hline 11. & Muttil (Fallow land) & $12^{\circ} 020^{\prime} .21$ & $75^{\circ} 16^{\prime} 20^{\prime \prime} .15$ \\
\hline 12. & MuttilVadakk & $12^{\circ} 014.80$ & $75^{\circ} 10^{\prime} 20^{\prime \prime} .70$ \\
\hline 13. & Muttil (Near Juma Masjid) & $12^{\circ} 013^{\prime} .39$ & $75^{\circ} 16^{\prime} 34^{\prime \prime} .16$ \\
\hline 14. & Muttil & $12^{\circ} 019^{\prime} .92$ & $75^{\circ} 16^{\prime} 33^{\prime \prime} .61$ \\
\hline 15. & Dam road & $11^{\circ} 59^{\prime} 45.94$ & $75^{\circ} 16^{\prime} 42^{\prime \prime} .34$ \\
\hline
\end{tabular}


Table.2 Physical properties of soil samples from different locations of Kaipad

\begin{tabular}{|c|c|c|c|c|c|c|}
\hline \multirow[t]{2}{*}{ Location } & \multicolumn{3}{|c|}{ Particle size distribution } & \multirow[t]{2}{*}{ Texture } & \multirow{2}{*}{$\begin{array}{c}\text { Bulk density } \\
\left(\mathrm{Mgm}^{-3}\right)\end{array}$} & \multirow[t]{2}{*}{ Moisture (\%) } \\
\hline & Sand \% & Silt \% & Clay \% & & & \\
\hline 1 & 56.08 & 21.34 & 20.17 & Sandy clay loam & 1.15 & 19.95 \\
\hline 2 & 58.64 & 19.95 & 21.41 & Sandy clay loam & 1.10 & 55.38 \\
\hline 3 & 59.32 & 16.29 & 24.39 & Sandy clay loam & 1.16 & 19.31 \\
\hline 4 & 59.64 & 17.56 & 21.20 & Sandy clay loam & 1.12 & 15.74 \\
\hline 5 & 64.32 & 16.10 & 17.40 & Sandy loam & 1.15 & 86.76 \\
\hline 6 & 60.14 & 14.32 & 24.28 & Sandy clay loam & 1.13 & 49.28 \\
\hline 7 & 54.32 & 16.40 & 28.14 & Sandy clay loam & 1.16 & 20.21 \\
\hline 8 & 68.32 & 12.14 & 17.15 & Sandy loam & 1.10 & 28.55 \\
\hline 9 & 56.34 & 19.95 & 22.58 & Sandy clay loam & 1.17 & 41.81 \\
\hline 10 & 47.32 & 25.14 & 26.12 & Sandy clay loam & 1.09 & 15.27 \\
\hline 11 & 49.65 & 27.31 & 20.20 & Loam & 1.06 & 24.65 \\
\hline 12 & 51.14 & 22.02 & 26.05 & Sandy clay loam & 1.13 & 31.25 \\
\hline 13 & 61.9 & 13.2 & 22.7 & Sandy clay loam & 1.11 & 23.45 \\
\hline 14 & 55.64 & 25.61 & 18.60 & Sandy loam & 1.15 & 29.54 \\
\hline 15 & 48.57 & 23.17 & 25.20 & Sandy clay loam & 1.10 & 18.56 \\
\hline
\end{tabular}


Table.3 Chemical properties of soil samples from different locations of Kaipad

\begin{tabular}{|c|c|c|c|c|c|c|c|c|c|}
\hline $\begin{array}{c}\text { Parameter } \\
\text { Location }\end{array}$ & $\mathbf{p H}$ & $\begin{array}{c}\mathrm{EC} \\
\left(\mathrm{dSm}^{-1}\right)\end{array}$ & Org. C (\%) & $\begin{array}{r}\text { Avail. N } \\
\left(\text { kgha }^{-1}\right)\end{array}$ & Avail. P $\left(\mathrm{kgha}^{-1}\right)$ & Avail. K (kgha $\left.{ }^{-1}\right)$ & Avail. Ca $\left(\mathrm{mgkg}^{-1}\right)$ & Avail. Mg $\left(\mathrm{mgkg}^{-1}\right)$ & Avail. S (mgkg $\left.{ }^{-1}\right)$ \\
\hline 1 & 4.72 & 14.3 & 1.75 & 577.65 & 35.44 & 2738.9 & 1216.25 & 37.25 & 1314.25 \\
\hline 2 & 3.96 & 27.00 & 2.34 & 756.4 & 45.21 & 3325.81 & 1400.00 & 43.60 & 926.84 \\
\hline 3 & 4.66 & 22.00 & 2.4 & 778.98 & 9.77 & 3717.08 & 2125.00 & 41.50 & 1534.62 \\
\hline 4 & 5.08 & 18.50 & 1.65 & 536.25 & 29.30 & 3130.17 & 1875.00 & 39.90 & 1529.09 \\
\hline 5 & 3.99 & 18.80 & 1.63 & 526.48 & 11.21 & 2086.78 & 1462.50 & 29.95 & 1437.21 \\
\hline 6 & 3.40 & 24.00 & 1.47 & 477.92 & 8.65 & 1369.45 & 2250.00 & 34.85 & 897.34 \\
\hline 7 & 5.33 & 12.60 & 1.53 & 494.86 & 11.28 & 2869.32 & 1825.00 & 35.25 & 748.77 \\
\hline 8 & 3.67 & 19.80 & 1.34 & 434.64 & 23.27 & 2151.99 & 2587.50 & 34.30 & 1316.99 \\
\hline 9 & 5.02 & 25.00 & 1.13 & 365.03 & 50.27 & 1825.93 & 1625.00 & 28.55 & 1452.20 \\
\hline 10 & 5.67 & 17.60 & 2.28 & 739.84 & 14.76 & 4630.05 & 3275.00 & 42.05 & 994.52 \\
\hline 11 & 6.48 & 12.00 & 3.34 & 1083.8 & 17.14 & 3391.02 & 2675.00 & 36.90 & 955.07 \\
\hline 12 & 5.23 & 29.00 & 1.43 & 466.63 & 15.94 & 4463.2 & 1925.00 & 34.60 & 994.20 \\
\hline 13 & 5.26 & 16.70 & 0.53 & 173.47 & 12.29 & 1239.02 & 826.25 & 21.30 & 813.71 \\
\hline 14 & 5.17 & 11.25 & 1.13 & 373.21 & 28.40 & 1983.21 & 1763.27 & 40.70 & 859.71 \\
\hline 15 & 5.07 & 9.72 & 1.21 & 389.12 & 43.65 & 3210.25 & 1964.28 & 34.90 & 1189.23 \\
\hline
\end{tabular}

Table.3 Contd: Chemical properties of soil samples from different locations of Kaipad

\begin{tabular}{|c|c|c|c|c|c|c|c|c|c|}
\hline $\begin{array}{c}\text { Parameter } \\
\text { Location } \\
\end{array}$ & $\begin{array}{c}\text { Avail. Fe } \\
\left(\mathrm{mgkg}^{-1}\right)\end{array}$ & $\begin{array}{c}\text { Avail. Zn } \\
\left(\text { mgkg }^{-1}\right)\end{array}$ & $\begin{array}{c}\text { Avail. } \\
\left.\text { Cu(mgkg }{ }^{-1}\right)\end{array}$ & $\begin{array}{c}\text { Avail. Mn } \\
\left(\mathrm{mgkg}^{-1}\right)\end{array}$ & $\begin{array}{l}\text { Avail. B } \\
\left(\text { mgkg }^{-1}\right)\end{array}$ & $\begin{array}{l}\text { Avail. Si } \\
\left(\mathrm{mgkg}^{-1}\right)\end{array}$ & $\begin{array}{l}\text { Exch. Al } \\
\left(\mathrm{mgkg}^{-1}\right)\end{array}$ & $\begin{array}{l}\text { Exch. Na } \\
\left(\mathrm{mg} \mathrm{kg}^{-1}\right)\end{array}$ & $\begin{array}{c}\text { CEC (meq/ } \\
100 \mathrm{~g})\end{array}$ \\
\hline 1 & 850 & 2.11 & 5.58 & 13.6 & 1.7 & 80.60 & 249 & 760 & 74.61 \\
\hline 2 & 728 & 3.33 & 4.68 & 9.21 & 1.63 & 54.50 & 314 & 1080 & 61.74 \\
\hline 3 & 1220 & 2.91 & 5.23 & 20.8 & 1.55 & 48.90 & 254 & 960 & 88.07 \\
\hline 4 & 809 & 4.96 & 6.78 & 15.5 & 1.5 & 108.00 & 266 & 880 & 157.57 \\
\hline 5 & 950 & 3.98 & 3.9 & 17.1 & 1.55 & 139.00 & 212 & 700 & 59.91 \\
\hline 6 & 1210 & 1.81 & 2.07 & 4.65 & 1.64 & 93.60 & 160 & 830 & 26.78 \\
\hline 7 & 1230 & 7.51 & 5.62 & 17.9 & 1.77 & 111.80 & 368 & 740 & 104.22 \\
\hline 8 & 1050 & 4.06 & 3.27 & 13.2 & 1.53 & 68.10 & 204 & 820 & 77.46 \\
\hline 9 & 991 & 1.93 & 3.44 & 11.7 & 1.56 & 163.00 & 168 & 730 & 65.11 \\
\hline 10 & 1240 & 7.66 & 5.97 & 25.46 & 1.76 & 647.90 & 434 & 960 & 184.46 \\
\hline 11 & 1250 & 11.5 & 4.00 & 8.9 & 1.66 & 671.90 & 381 & 760 & 124.89 \\
\hline 12 & 1180 & 5.62 & 2.54 & 3.4 & 1.79 & 110.50 & 245 & 840 & 45.26 \\
\hline 13 & 702 & 3.39 & 4.57 & 7.52 & 1.7 & 124.40 & 223 & 530 & 21.91 \\
\hline 14 & 895 & 2.14 & 3.65 & 9.45 & 1.53 & 82.60 & 256 & 650 & 55.28 \\
\hline 15 & 952 & 1.98 & 4.91 & 12.24 & 1.29 & 76.30 & 213.6 & 580 & 42.72 \\
\hline
\end{tabular}


Table.4 Minimum and maximum values, mean and standard deviation of chemical properties of 15 soil samples of Kaipad

\begin{tabular}{|c|c|c|c|c|c|}
\hline \multirow[t]{2}{*}{ S.No. } & \multirow[t]{2}{*}{ Parameter } & \multicolumn{2}{|c|}{ Range } & \multirow[t]{2}{*}{ Mean value } & \multirow{2}{*}{$\begin{array}{l}\text { Standard } \\
\text { deviation }\end{array}$} \\
\hline & & Minimum value & Maximum value & & \\
\hline 1 & $\mathrm{pH}$ & 3.40 & 6.48 & 4.85 & 0.81 \\
\hline 2 & $\mathrm{EC}\left(\mathrm{dSm}^{-1}\right)$ & 9.72 & 29.00 & 18.55 & 5.96 \\
\hline 3 & Organic carbon $(\%)$ & 0.53 & 3.34 & 1.68 & 0.68 \\
\hline 4 & Available nitrogen $\left(\mathrm{kgha}^{-1}\right)$ & 173.47 & 1083.80 & 544.95 & 220.19 \\
\hline 5 & Available phosphorus $\left(\mathrm{kgha}^{-1}\right)$ & 8.65 & 50.27 & 23.77 & 14.15 \\
\hline 6 & Available potassium $\left(\mathrm{kgha}^{-1}\right)$ & 1239.02 & 4630.05 & 2808.81 & 1031.45 \\
\hline 7 & Available calcium $\left(\mathrm{mgkg}^{-1}\right)$ & 826.25 & 3275.00 & 1919.67 & 615.19 \\
\hline 8 & Available magnesium $\left(\mathrm{mgkg}^{-1}\right)$ & 21.30 & 43.60 & 35.71 & 5.85 \\
\hline 9 & Available sulphur $\left(\mathrm{mgkg}^{-1}\right)$ & 748.77 & 1534.62 & 1130.92 & 277.08 \\
\hline 10 & Available iron $\left(\mathrm{mgkg}^{-1}\right)$ & 702.00 & 1250.00 & 1017.13 & 195.24 \\
\hline 11 & Available zinc $\left(\mathrm{mgkg}^{-1}\right)$ & 1.81 & 11.50 & 4.33 & 2.75 \\
\hline 12 & Available copper $\left(\mathrm{mgkg}^{-1}\right)$ & 2.07 & 6.78 & 4.41 & 1.31 \\
\hline 13 & Available manganese $\left(\mathrm{mgkg}^{-1}\right)$ & 3.40 & 25.46 & 12.71 & 5.98 \\
\hline 14 & Available boron $\left(\mathrm{mgkg}^{-1}\right)$ & 1.29 & 1.79 & 1.61 & 0.13 \\
\hline 15 & Available silicon $\left(\mathrm{mgkg}^{-1}\right)$ & 48.90 & 195.00 & 109.52 & 45.14 \\
\hline 16 & Exchangeable aluminium $\left(\mathrm{mgkg}^{-1}\right)$ & 160.00 & 434.00 & 263.17 & 78.92 \\
\hline 17 & Exchangeable sodium $\left(\mathrm{mgkg}^{-1}\right)$ & 530.00 & 1080.00 & 788.00 & 146.93 \\
\hline 18 & CEC (meq/ $100 \mathrm{~g}$ ) & 21.91 & 184.46 & 79.33 & 46.29 \\
\hline
\end{tabular}




\section{Int.J.Curr.Microbiol.App.Sci (2017) 6(11): 1464-1475}

Fig.1 Map of Kaipad area from where soil samples were collected
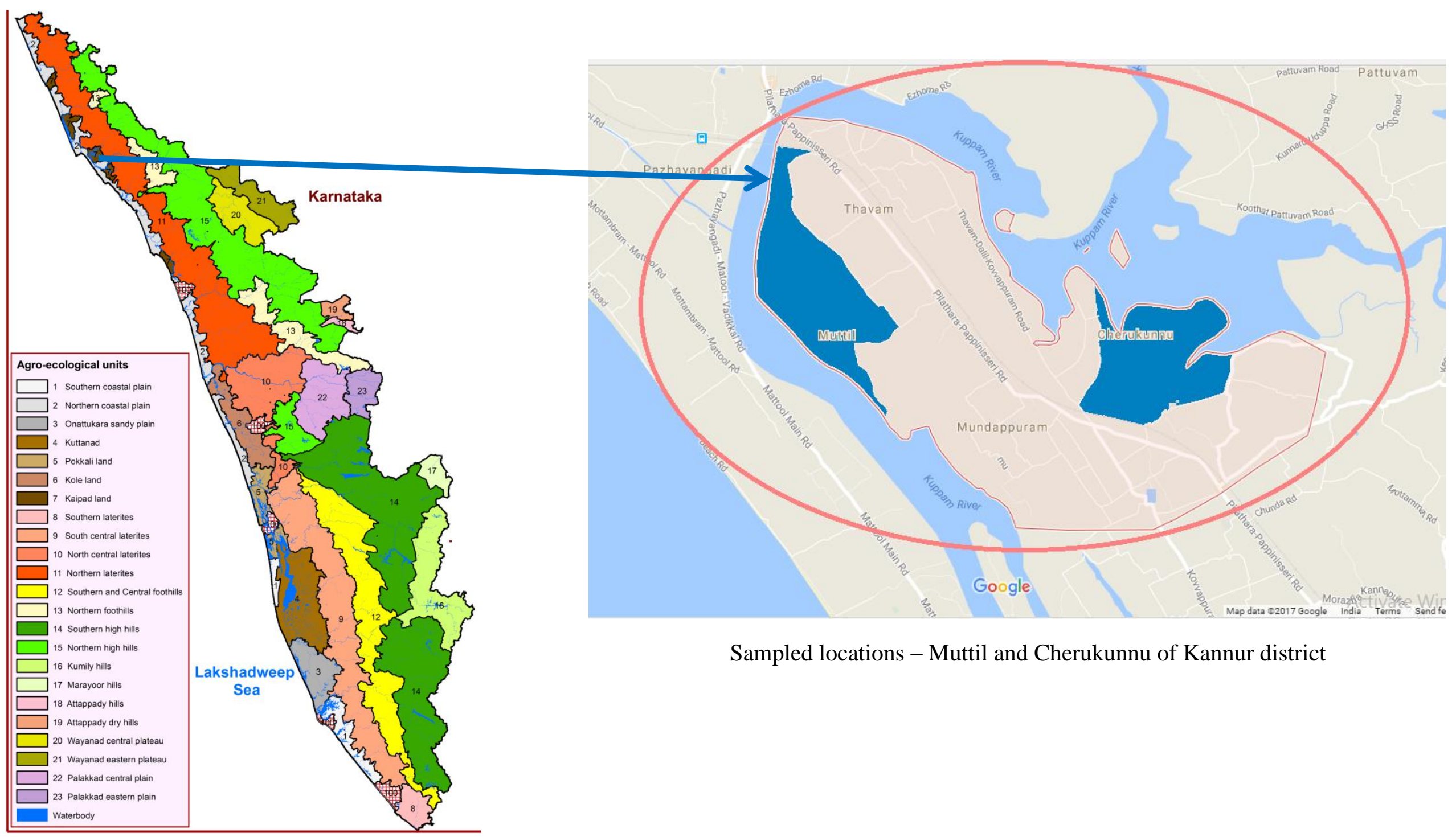

Sampled locations - Muttil and Cherukunnu of Kannur district

Agro-ecological zones of Kerala (7-Kaipad land) 
Fig.2 Soil pH in sampled areas of Kaipad

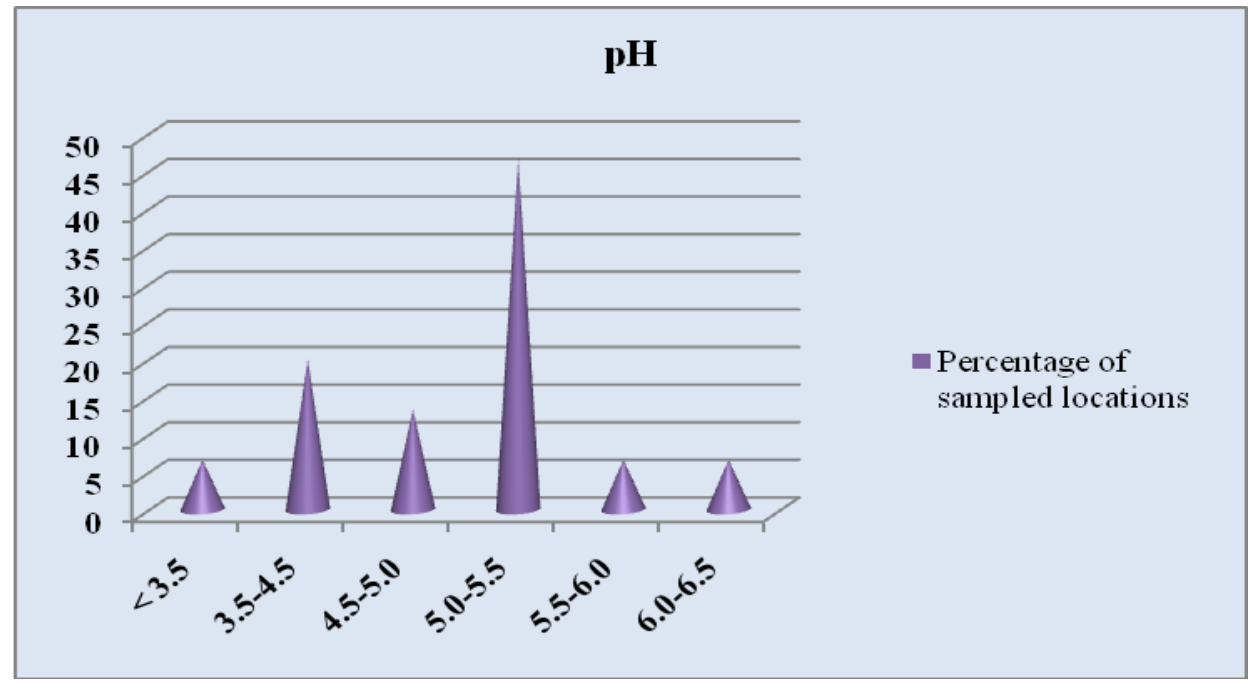

Plate.1 Collection of soil samples from a depth of 0 to $15 \mathrm{~cm}$

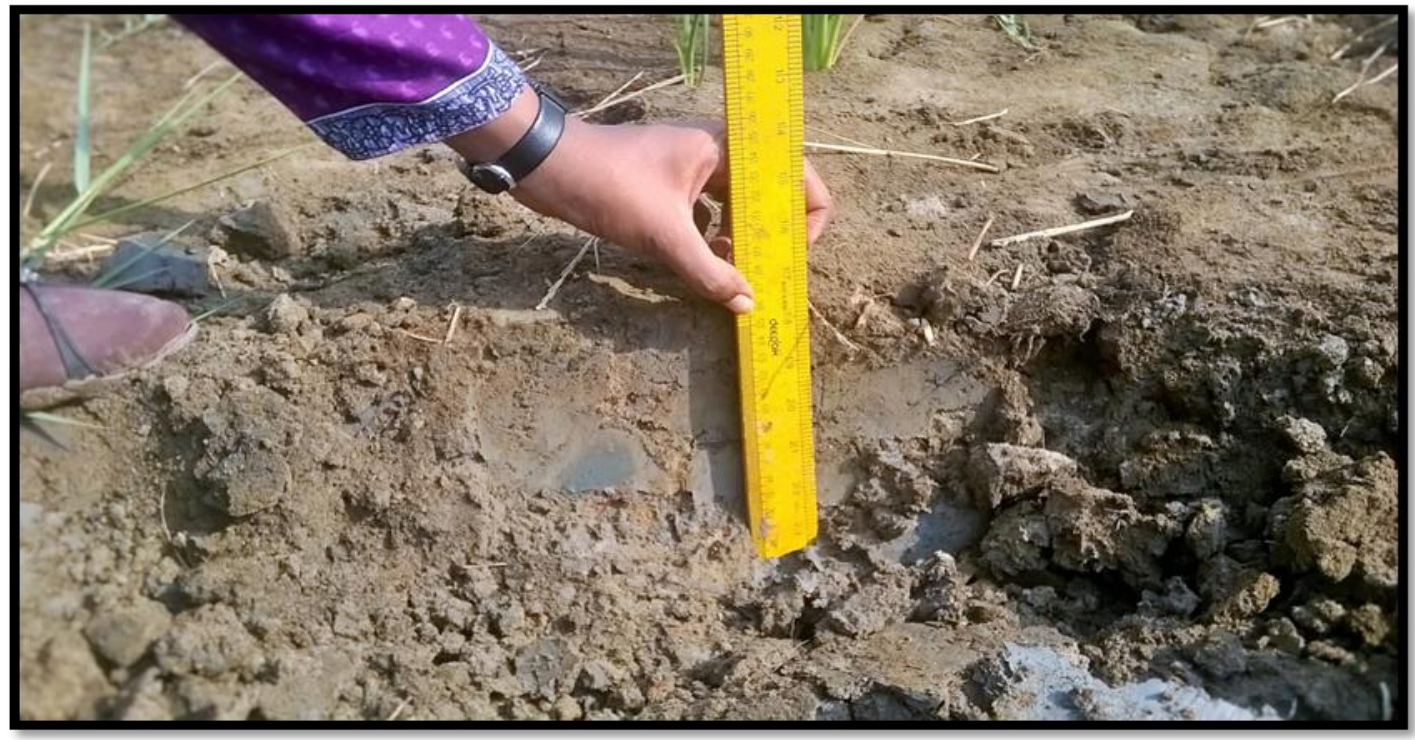

Irrespective of the high available calcium content, the present investigation revealed that the available magnesium content was very low. The status of available magnesium content of the study locations ranged from $21.30 \mathrm{mgkg}^{-1}$ to a maximum value of 43.60 $\mathrm{mgkg}^{-1}$ with a mean value of $35.71 \mathrm{mgkg}^{-1}$ (Table 4). The low magnesium content in the saline hydromorphic soils of Kaipad may be accounted to the presence of the cation in the exchange complex sites which is not readily available in the soil solution. The low status of magnesium in the saline hydromorphic soils of Pokkali was also reported by Varghese et al. (1970) and Samikutty (1977). They had reported that even though magnesium is a major exchangeable cation in the Pokkali soils, the presence of low status of magnesium may be accounted to its existence in the exchangeable complex. Aryalekshmi (2016) reported a magnesium content of 26.17 $\mathrm{mgkg}^{-1}$ in Pokkali soils. 
The available sulphur content of the soils varied from $43.60 \mathrm{mgk}^{-1}$ in location number 3 to $748.77 \mathrm{mgkg}^{-1}$ in location number 7 . The high extents of sulphur content can be credited to the presence of moderately high organic matter content in these soils. The high sulphur content may also be attributed to the presence of pyrites and other iron bearing minerals like jarosite (hydrous sulphate of potassium and iron). The presence of pyrites and other iron bearing minerals in Kaipad soils was reported by Iyer (1989).

\section{Available micronutrients}

The present investigation showed high available micronutrient content in all the sampled locations of Kaipad.

The available iron content in these soils varied from 702 to $1250 \mathrm{mgkg}^{-1}$ which was in toxic levels. Similar trend on iron content which varied from 171 to $2321 \mathrm{mgkg}^{-1}$ was reported by Shylaraj et al., (2013) in Pokkali soils. The presence of high iron may be accounted to the presence of soil minerals such as pyrites, jarosite etc. (Iyer, 1989). The availability of iron was found to increase on submergence (Ponnamperuma, 1972).

The available manganese content in these soils varied from 3.4 to $25.46 \mathrm{mgkg}^{-1}$. This revealed that available manganese was adequate in the sampled locations of Kaipad. There had been a report on the low manganese availability due to the presence of high organic matter (Mandal and Mitra, 1982). Malvi (2011) stated that the interaction of iron with manganese is antagonistic in nature. The toxic levels of iron content might have adversely affected the manganese content in the soils of Kaipad.

The available zinc values ranged from 1.81 to $11.50 \mathrm{mgkg}^{-1}$ in the sampled locations. The mean value of available zinc was recorded as
4.33. The values revealed that the available zinc content recorded in the sampled locations of Kaipad was adequate. Zinc forms chelate with the organic matter present in the soil. Chelated forms of zinc do not move through the soil and is not subjected to leaching losses (Schulte).

The available copper content in the sites ranged from 2.07 to $6.78 \mathrm{mgkg}^{-1}$ over the locations. Though the available copper content in the sampled locations were adequate, the status was low as compared to other nutrients. This might be attributed to the presence of copper as an impurity in silicate minerals or carbonates which renders copper unavailable in the soil pool. The organic matter present in the soil binds copper more tightly as compared to other micro nutrients (Schulte and Kelling).

The available boron content in the sampled locations ranged from 1.29 to $1.79 \mathrm{mgkg}^{-}$ ${ }^{1}$ over the locations. The high available boron status in the soils of Kaipad might be due to the incursion of sea water into these areas during the monsoon period. High boron content was observed with increase in salinity. Similar reports on high levels of boron were observed on Pokkali soils by Aditya, (2016).

\section{Exchangeable aluminium}

The exchangeable aluminium was found in higher concentrations varying from 160 to434 $\mathrm{mgkg}^{-1}$. The high aluminium content may be due to the acidic $\mathrm{pH}$ prevailing in those areas.Kochian (1995) also reported that aluminium is an element which gets solubilised into the soil solution at acidic $\mathrm{pH}$ values and thus become toxic to plants. The aluminium gets solubilised from silicate clays and hydrous oxides of aluminium at a $\mathrm{pH}$ below 5.3, thus increasing the activity of exchangeable aluminium (Aditya, 2016). 


\section{Available silicon}

High available silicon content was observed in these soils varying from $48.90 \mathrm{mgkg}^{-1}$ to $195.00 \mathrm{mgkg}^{-1}$. The accumulation of oceanic derived or marine derived salt deposits augments the acidity due to various exchange processes (Harriman et al 1995). Additions of these salts enhances the strength of aqueous $\mathrm{Fe}^{2+}, \mathrm{Al}^{3+}$ and Si resulting in decreasing $\mathrm{pH}$ of these soils (Mkadam et al 2006).

\section{Exchangeable sodium}

The exchangeable sodium content in the soils varied from $530 \mathrm{mgkg}^{-1}$ to $1080 \mathrm{mgkg}^{-1}$ which was very high. The presence of high sodium can be linked to the frequent intrusion of sea water containing soluble salts. The ESP of the sampled locations varied from 2.26 to 13.48 per cent. Similar findings on exchangeable sodium percentage ranging from 13.7 to 83.3 in Pokkali soils were reported by Samikutty (1977).

\section{Cation exchange capacity}

The cation exchange capacity varied from $21.91 \mathrm{cmol}\left(\mathrm{P}^{+}\right) \mathrm{kg}^{-1}$ to $184.46 \mathrm{cmol}\left(\mathrm{P}^{+}\right) \mathrm{kg}^{-1}$ in location numbers 13 and 10 respectively. This high CEC may be accredited to the interaction between organic matter and clay minerals. Curtin and Rostad (1997) stated that the cation exchange capacity of the clays and the organic matter are held as additives. The richness in organic matter of the soil contributing to high CEC might be accounted to the integrated farming system in which rice and aquaculture is practised together.

The incorporation of stubbles in the field after harvest of rice crop (Vanaja, 2013) also adds organic matter to the soil contributing to high CEC. Soumya (2016) conveyed that some regions of Kaipad tracts showed a trend in CEC ranging from 11.67 to $13.7 \mathrm{cmol}\left(\mathrm{P}^{+}\right) \mathrm{kg}$
Relatively high values of $\mathrm{pH}$, organic carbon, available nitrogen, potassium and calcium can be attributed to the fallow nature of the sampled sites compared to other sites where rice-fish aquaculture is regularly practised.

\section{References}

Aditya, M. (2016) Ion interactions and rice nutrition in acid saline pokkali soils. $\mathrm{M}$. Sc. (Ag) thesis, Kerala Agricultural University, Thrissur. pp. 223.

Aryalekshmi, V. (2016) Silicon availability of tropical soils with respect to rice nutrition. M. Sc. (Ag) thesis, Kerala Agricultural University, Thrissur, 236p.

Chandramohan, K. T. and Mohanan. K. V. (2012)Kaipad rice farming in North Kerala - An indigenous saline resistant organic farming system. Indian $J$. Traditional Knowl. 11(1): pp. 185-189.

Curtin, O. and Rostad, H. P. W. (1997) Cation exchange and buffer potential of Saskatchewan soils estimated from texture, organic matter and $\mathrm{pH}$. Can. J. Soil Sci. 77: pp. 621-626.

Iyer, M. S. (1989) Studies on macromeso and micromorphology and clay mineralogy of the acid sulphate soils of Kerala. PhD thesis, Kerala Agricultural University, Thrissur.

Kochian, K. V. (1995) Cellular mechanisms of aluminium toxicity and resistance in plant.Annu. Rev. Plant Physiol. Mol. Biol. 46: pp. 237-260.

Leiros, M. C.et al. (1999) Dependence of mineralization of soil organic matter on temperature and moisture. Soil Biol.Biochem. 31: pp. 327-335.

Malvi, U. R. (2011) Interaction of micronutrients with major nutrients with special reference to potassium. Karnataka J. Agric. Sci. 24(1): pp. 106109.

Mandal, L. N. and Mitra, R. R. (1982) Transformation of iron and manganese in rice soils under different moisture 
regimes and organic matter applications. Plant Soil 69(1): pp. 4546.

Mkadam, K. M.et al.(2006) Dissolved aluminium and silica release on the interaction of Okinawan subtropical red soil and seawater at different salinities: experimental and field observations. Geochemical J. 40: pp. 333-343.

Nair, P. G. and Money, N. S. (1972) Studies on some chemical and mechanical properties of salt affected rice soils of Kerala. Agric. res. J. Kerala 10(1): pp. 51-53.

Padmakumar, K. G.et al. (2002) Thanneermukkom barrage and fishery decline in Vembanad wetlands, Kerala. In: Kamalakshan, K., Premachandran, P. N. and Bijukumar, A. (eds), Wetland conservation and management in Kerala. State Committee on Science, Technology and Environment, Thiruvananthapuram, Kerala, pp. 27-36.

Ponnamperuma, F. N. (1972) The chemistry of submerged soils. Adv. Agron. 24: pp. 29-96.

Samikutty, V. 1977.Investigations on the salinity problems of Pokkali and Kaipad areas of Kerala State.M. Sc. (Ag) thesis, Kerala Agricultural University, Thrissur.

Schulte, E. E. and Kelling, K. A., n.d., Soil and applied copper, A2527, Understanding plant nutrients, University of Wisconsin System Board of Regents and University of
Wisconsin- Extension, Cooperative Extension, U.S.A. Available: http://corn.agronomy.wisc.edu/Manage ment/pdfs/a2527.pdf [05 Aug.2017].

Schulte, E. E., Soil and applied zinc, A2528, Understanding plant nutrients, University of Wisconsin System Board of Regents and University of Wisconsin- Extension, Cooperative Extension, U.S.A. Available: http://corn.agronomy.wisc.edu/Manage ment/pdfs/a2528.pdf [05 Aug.2017].

Shylaraj, K. S. and Sasidharan, N. K. (2005) VTL5: A high yielding salinity tolerant rice variety for the coastal saline ecosystems of Kerala. J. Trop. Agric. 43(1-2): pp. 25-28.

Shylaraj, K. S. et al. (2013) Five decades of glorious research at the Rice Research Station, Vyttila: 1958-2013. Directorate of extension, Kerala Agricultural University, Thrissur, 80p.

Vanaja, T. (2013) KAIPAD -a unique, naturally organic, saline prone rice ecosystem of Kerala, India. Am. J. Environ. Prot. 2(2): pp. 42-46.

Vanaja, T.et al. (2015) The first high yielding saline tolerant rice variety suited to the Kaipad tidal farming ecosystem of Kerala, India, and suited for flood prone and water scarce environments: 'Ezhome-1'. J. Org. 2(1): pp. 21-31.

Varghese, T. et al. (1970) Some preliminary studies on the Pokkali saline soils of Kerala. J. Indian Soc. Soil Sci. 18: pp. 65-70.

\section{How to cite this article:}

Santhi, G.R., N.K. Binitha, P.R. Suresh and Ebimol, N.L. 2017. Assessment of Physical and Chemical Properties of Soil Samples in Kaipad Tracts of Kannur District, India. Int.J.Curr.Microbiol.App.Sci. 6(11): 1464-1475. doi: https://doi.org/10.20546/ijcmas.2017.611.175 